\title{
Cobalt hexacyanoferrate as a selective and high current den- sity formate oxidation electrocatalyst
}

\author{
Lijuan Han, ${ }^{\dagger}$ Jesús González-Cobos, ${ }^{\dagger}$ Irene Sánchez-Molina, ${ }^{\dagger}$ Stefano Giancola, ${ }^{\dagger}$ Scott J. Folk- \\ man, ${ }^{\dagger}$ Pengyi Tang, ${ }^{\S}$ Marc Heggen, ${ }^{\sharp}$ Rafal E. Dunin-Borkowski, ${ }^{\sharp}$ Jordi Arbiol, ${ }^{\S} \uparrow$ Sixto Giménez, ${ }^{\perp}$ \\ and Jose Ramon Galan-Mascaros*,+,
}

†Institute of Chemical Research of Catalonia (ICIQ), The Barcelona Institute of Science and Technology (BIST), Av.
Paisos Catalans 16, 43007 Tarragona, Spain.
\$Catalan Institute of Nanoscience and Nanotechnology (ICN2), CSIC and BIST, Campus UAB, Bellaterra, o8193 Bar-
celona, Catalonia, Spain.

\#Ernst-Ruska Centre for Microscopy and Spectroscopy with Electrons and Peter Grünberg Institute, Forschungszentrum Jülich GmbH, 52425 Jülich, Germany.

IICREA, Pg. Lluís Companys 23, o8010 Barcelona, Spain.

${ }^{\perp}$ Institute of Advanced Materials (INAM), Universitat Jaume I, 12006 Castelló, Spain.

\begin{abstract}
Herein we report the selectivity, stability, and electrochemical characterization of cobalt hexacyanoferrate, the CoFe Prussian Blue derivative (CoFePB), as a formate/formic acid oxidation electrocatalyst in aqueous media. CoFePB is able to quantitatively catalyze (100\% Faradaic efficiency within less than $8 \%$ standard error at $\mathrm{pH}$ 5) the electrochemical oxidation of formate to $\mathrm{CO}_{2}$ over a $\mathrm{pH}$ range of 1-13. This quantitative formate elecrooxidation is possible due to the exclusive selectivity of the catalyst in a wide potential window (from c.a. 0.8 to $1.3 \mathrm{~V}$ vs. NHE at $\mathrm{pH}$ 7), where no other substrate in aqueous conditions is activated: neither other organic molecules, such as alcohols or acids, nor water itself. CoFePB is one of the first heterogeneous noble-metal-free catalysts reported for the electrooxidation of small hydrocarbon molecules. Importantly, the catalyst showed a very high tolerance against surface poisoning during the reaction, as supported by the cyclic voltammetry and electrochemical impedance spectroscopy data, thereby allowing CoFePB to operate at greater current density than state-of-the-art noble metal catalysts. For example, we observed that $\mathrm{CoFePB}$ is able to achieve a formate oxidation current $\sim 10 \mathrm{~mA} \mathrm{~cm}^{-2}$ at $\mathrm{pH} 5,0.4 \mathrm{M}$ formate at $1.1 \mathrm{~V}$ vs NHE, whereas a Pt disk and $\mathrm{Pd}(5 \%) / C$ electrodes had a current of 0.4 and $1.4 \mathrm{~mA} \mathrm{~cm}^{-2}$, respectively, under identical conditions. The remarkable selectivity, stability, and high current density of CoFePB, in contrast to state-of-the-art catalysts based on platinum-group metals (PGM), is an important step in the search for inexpensive earth-abundant materials for oxidation of organic molecules for use in liquid fuel cells or for selective organic molecule sensors. Furthermore, because CoFePB is not poisoned by intermediates and can achieve higher current density than Pt or Pd, improvement of the catalyst onset potential can lead to higher power density formate oxidation fuel cells using earth abundant metals than with Pt or Pd.
\end{abstract}

\section{Introduction}

The selective electrochemical oxidation of small organic molecules is getting attention for multiple applications, including sensing and analysis, environmental remediation and energy-related systems, such as fuel cells. In the latter sense, liquid hydrogen carriers (alcohols, acids, sugars) have been proposed as potential $\mathrm{H}_{2}$ storage media, given their high volumetric energy density and ease of transport, handling and storage. ${ }^{-6}$ Furthermore, direct liquid fuel cells could be an alternative, more practical system compared to hydrogen fuel cells. In particular, direct formic acid fuel cells or direct formate fuel cells present higher theoretical cell voltage than fuel cells running on methanol or ethanol. Additionally, formate can be produced from $\mathrm{CO}_{2}$ reduction by renewable energy sources, thereby forming a carbon-neutral fuel cycle. ${ }^{7,8}$ Formate is also highly soluble in water, thereby avoiding flammable organic solvents and leading to safer operation. Regarding the sensing field, selective formate/formic acid electrooxidation materials are important, for instance, in analysis of pollutants in the atmosphere and natural waters, detection of liquid fuel cell crossover or control of aerobic and anaerobic fermentation processes. ${ }^{9-12}$

Electrooxidation catalysts for small organic molecules are typically non-selective, and mostly based on noble metals or platinum-group metals (PGM) like Pt or Pd. Furthermore, these catalysts may be subject to poisoning by intermediate products or impurities. ${ }^{13,14}$ Noble-metal-free electrocatalysts towards the anodic oxidation of small hydrocarbon molecules are scarce. ${ }^{1,15}$ Thus, we are interested in catalysts made of earth-abundant materials for the selective aqueous oxidation of formate/formic acid. There are few studies on $\mathrm{HCOO}^{-} / \mathrm{HCOOH}$ electrooxidation where some transition metals are employed in conjunction with 
Pd or Pt. ${ }^{16-19}$ To our knowledge, there is only one work, from Bisht et al., ${ }^{20}$ where a fully noble-metal-free catalyst is employed. In this study, the authors tested a perovskitetype catalyst, $\mathrm{La}_{0.8} \mathrm{Sr}_{0.2} \mathrm{CoO}_{3}$, in a o.5 $\mathrm{M} \mathrm{KNO}_{3}$ electrolyte solution containing $\mathrm{HCOOH}$ (2.1 M) and, interestingly, they observed some formic acid oxidation even under open circuit conditions, which was attributed to the contribution of lattice oxygen. However, the reaction rate in these conditions was sluggish and only reached a maximum of $\sim 2$ $\mathrm{mA} \mathrm{cm} \mathrm{cm}^{-2}$ at $1.3 \mathrm{~V}$ vs. NHE. There are few more non-noble metal catalysts for formic acid oxidation but they work under very limited conditions. For example, dehydrogenase enzymes are very sensitive to temperature, $\mathrm{pH}$, etc. and lack long-term stability. ${ }^{21,22}$ The only synthetic homogeneous electrocatalysts with high activity towards formate oxidation, the family of $\left[\mathrm{Ni}\left(\mathrm{PR}_{2} \mathrm{NRO}_{2}\right)_{2}\left(\mathrm{CH}_{3} \mathrm{CN}\right)\right]^{2+}$ catalysts, ${ }^{23,24}$ can only work in ultrapure organic solvents and are sensitive to trace amounts of water, air or other impurities.

As plausible oxidation catalyst for organic substrates, we investigated cobalt hexacyanoferrate ( $\mathrm{CoFePB})$, a versatile and robust oxidation catalyst in a wide $\mathrm{pH}$ range, with a proven performance in water oxidation (photo)electrocatalysis. ${ }^{25-28}$ In the present work we have found that CoFePB offers excellent selectivity and efficiency towards aqueous $\mathrm{HCOO}^{-}$oxidation under a $\mathrm{pH}$ range of 1-13. Its performance was evaluated electrochemically and has been compared with that of state-of-the-art catalysts, also providing mechanistic insights on the reaction kinetics. To our knowledge, CoFePB is the first earth abundant heterogeneous electrocatalyst for the selective oxidation of formate/formic acid in water, and unique when compared to the commonly used but expensive Pt-or Pd-based catalysts.

\section{Experimental Section}

Materials and chemicals. All chemicals used were analytical reagent grade, and included, cobalt (II) nitrate hexahydrate $\mathrm{Co}\left(\mathrm{NO}_{3}\right)_{2} 6 \mathrm{H}_{2} \mathrm{O}$ (Aldrich), urea $98 \% \mathrm{CH}_{4} \mathrm{NO}_{2}(\mathrm{Al}-$ drich), potassium hexacyanoferrate $\mathrm{K}_{3} \mathrm{Fe}(\mathrm{CN})_{6}$ (Aldrich), $98 \%$ formic acid solution (Aldrich), 63-67\% nitric acid (Aldrich) and $98 \%$ sulfuric acid (Aldrich). All solutions were prepared using $18.2 \mathrm{M} \Omega \cdot \mathrm{cm}$ Milli-Q water. If not specified, all commercially available reagents and solvents were used as received without further purification.

Fluorine-doped tin oxide (FTO) coated glass slides (12 - 14 $\Omega$ per square surface resistivity) were purchased from Pilkington NSG TEC 15A $2.2 \mathrm{~mm}$ slides with 80.0 - 81.5\% transmittance. Pt foil (99.95 \%, $0.1 \mathrm{~mm}$ thickness) was purchased from Goodfellow. FAA-3 anionic binder ( $5 \%$ solution) was purchased from Fumatech.

Electrode preparation. The CoFePB electrodes were prepared following a typical synthetic procedure ${ }^{25}$ where a thin pink film of $\mathrm{CoO}_{x}$ with a $1 \times 1 \mathrm{~cm}^{2}$ geometric surface area was initially grown on a transparent FTO surface by hydrothermal method. The $\mathrm{CoO}_{\mathrm{x}} / \mathrm{FTO}$ sample was subsequently placed in the freshly prepared $800 \mathrm{mg} / 100 \mathrm{~mL}$ $\mathrm{K}_{3} \mathrm{Fe}(\mathrm{CN})_{6}$ aqueous solution and heated at $60{ }^{\circ} \mathrm{C}$ for 24 hours. Finally, CoFePB sample was immersed in the concentrated $\mathrm{H}_{2} \mathrm{SO}_{4}$ solution ( $\mathrm{pH}$ ) for more than 4 hours to remove any possible remaining traces of oxide, and then rinsed with MilliQ water. The average CoFePB mass loading on the electrodes is $0.3 \mathrm{mg} \mathrm{cm}^{-2}$.

The structure of the CoFePB electrodes was characterized by means of aberration-corrected scanning transmission electron microscopy (STEM) in high angle annular dark field (HAADF) mode. From the atomic resolution HAADF STEM images acquired we obtained Fast Fourier Transform (FFT) power spectra in selected regions and indexed the patterns obtaining that the sample structure was in good agreement with the $\mathrm{Co}_{4}\left[\mathrm{Fe}(\mathrm{CN})_{6}\right]_{2.67} \cdot \mathrm{H}_{2} \mathrm{O}_{15.33}$ crystal phase. ${ }^{25}$ Additional electron energy loss spectroscopy (EELS) chemical composition maps were also obtained, corioborating the above composition (Figures 1, S1 and S2).

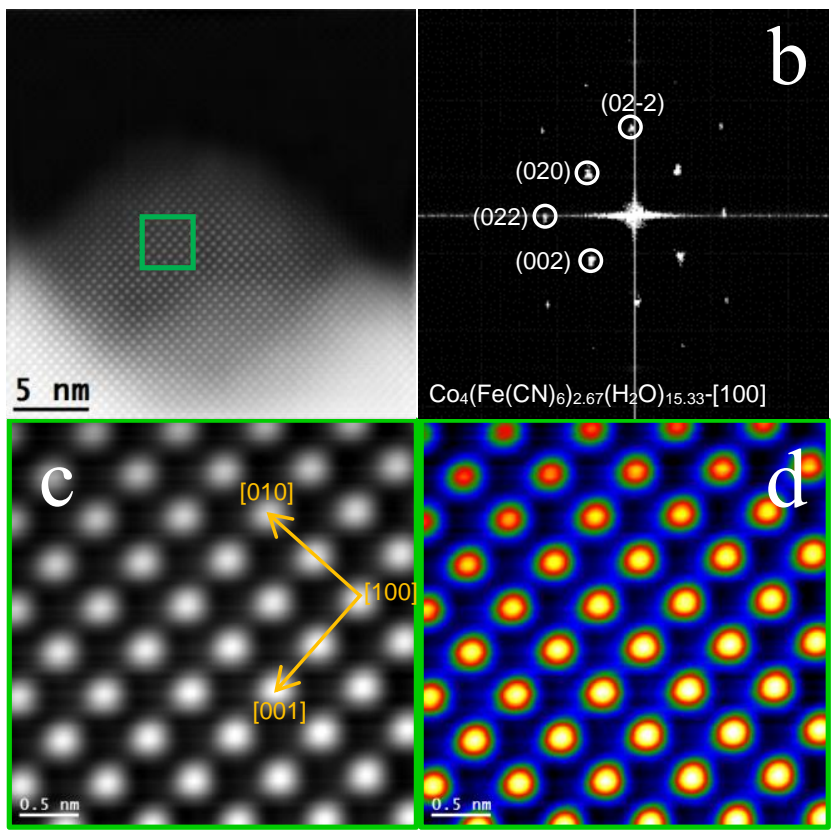

Figure 1. (a) Atomic resolution HAADF STEM image showing the edge a nanocube. (b) Respective power spectrum (FFT) confirming that the nanocube structure is in agreement with the $\mathrm{Co}_{4}\left(\mathrm{Fe}(\mathrm{CN})_{6}\right)_{2.67}\left(\mathrm{H}_{2} \mathrm{O}\right)_{15.33}\left(\mathrm{FM}_{3}-\mathrm{M}\right.$, Space group: 225) crystal phase in the [100] direction. (c-d) Enlarged image from the green squared section in both grey and temperature colored scales.

For comparison purposes, a commercial Pt disk electrode (0.07 $\mathrm{cm}^{2}$ geometric area) and a carbon-supported Pd catalyst with $5 \%$ metal content deposited on FTO $\left(1 \times 1 \mathrm{~cm}^{2}\right.$ geometric area) were also electrochemically tested. The $\mathrm{Pd}(5 \%) / \mathrm{C}$ ink was prepared by a procedure adapted from the literature ${ }^{29}$ by mixing $30 \mathrm{mg}$ of commercially available $\mathrm{Pd}(5 \%) /$ Vulcan carbon with $25 \mu \mathrm{L}$ of $5 \%$ FAA-3 anionic binder and 9.75 $\mathrm{mL}$ of a 3:1 EtOH/water solution and sonicating for 30 minutes. FTO coated glass slides were cut into $3 \times 1 \mathrm{~cm}^{2}$ strips, then sonicated in a soap water solution for $10 \mathrm{~min}$, rinsed thoroughly with distilled water, sonicated in ethanol $10 \mathrm{~min}$, rinsed thoroughly with ethanol, and finally sonicated in acetone for 10 minutes before allowing to air dry. The $\mathrm{Pd}(5 \%) / C$ ink was then sprayed onto the FTO substrate that had been masked with Kapton tape to expose only a $1 \mathrm{x} 1 \mathrm{~cm}^{2}$ surface area on a hot plated heated to $80^{\circ} \mathrm{C}$. The electrode was weighed before and after the coating to obtain the mass of added catalyst and was typically between 1.5 and $2 \mathrm{mg}$ of $\mathrm{Pd}(5 \%) / C$ per $1 \mathrm{~cm}^{2}$ electrode surface area. 
Electrochemical methods. All electrochemical experiments were conducted under ambient conditions, with a computer-controlled Bio-Logic $\mathrm{VMP}_{3}$ multichannel potentiostat. In order to maintain a constant ionic strength, $1 \mathrm{M}$ $\mathrm{KNO}_{3}$ was added to reduce the impact stemmed from mass diffusion and to ensure a good ionic conductivity. The $\mathrm{pH}$ was adjusted by adding aliquotes of concentrated $\mathrm{KOH}$ or $\mathrm{HNO}_{3}$. The total electrolyte volume was $30 \mathrm{~mL}$.

For our study, we employed a standard three-electrode arrangement with a Pt mesh counter electrode, and a saturated calomel electrode (SCE) as reference electrode. The potentiodynamic polarization curves were recorded at a scan rate of $20 \mathrm{mV} \mathrm{s}^{-1}$ without magnetic stirring, while the quasi-steady-state polarization curves were measured at a sweep rate of $5 \mathrm{mV} \mathrm{s}^{-1}$ under magnetic stirring. Chronoamperometric measurements (CA) were conducted at a constant applied potential under vigorous stirring in a $\mathrm{H}$ shaped cell with medium porosity glass frits. Steady-state current densities for Tafel analyses were collected at a variety of applied potentials within formate electrocatalytic oxidation windows. Working potential was swept from low to high values with $40 \mathrm{mV}$ increments. At each potential, the current was stabilized for 10 minutes to attain a steadystate value with the stirred solution $(600 \mathrm{rpm})$. All potentials reported in this paper are expressed vs. NHE unless otherwise indicated by adding $+0.241 \mathrm{~V}$ to the potential vs. SCE. Current densities are always normalized to the corresponding geometric surface area.

$\mathrm{CO}_{2}$ evolution efficiency. The theoretical $\mathrm{CO}_{2}$ amount was calculated from the total amount of charge $(\mathrm{Q})$ passed through the electrode during CA measurements, taking into account that two electrons are required to produce one $\mathrm{CO}_{2}$ molecule. The experimental amount of $\mathrm{CO}_{2}$ produced was quantitatively determined by using a calibrated Mass Spectrometer (MS). Mass-to-charge ratios (m/z) of 2, $12,14,16,17,18,22,28,30,32,44,46$ and 47 were continuously monitored with a quadrupole mass spectrometer (Pffeifer OmniStar GSD $301 \mathrm{C}$ ) during different chronopotentiometries carried out in the three-electrode cell under $\mathrm{N}_{2}$ bubbling ( $50 \mathrm{NmL} \mathrm{min}^{-1}$ ). The experimental flows were estimated from the MS signals obtained for $\mathrm{m} / \mathrm{z}=22$ and 44 , which were previously calibrated with certified standards (Air Liquide) of $\mathrm{CO}_{2}\left(99.999 \%\right.$ purity and $1.5 \%$ in $\mathrm{N}_{2}$ ) and the $\mathrm{N}_{2}$ flow was controlled by a mass flowmeter (Bronkhorst EL-FLOW).

A chronoamperometry experiment was also performed without $\mathrm{N}_{2}$ flow through the cell in order to perform static analysis of the headspace (volume of $23 \mathrm{NmL}$ ) with an $\mathrm{Ag}$ ilent $7820 \mathrm{~A}$ gas chromatography (GC) system equipped with columns Washed Molecular Sieve 5A, 2m x 1/8" OD, Mesh 6o/8o SS and Porapak Q, 4m x 1/8" OD, SS. Mesh: 8o/10o SS and a Thermal Conductivity Detector. ${ }^{1} \mathrm{H}$ and ${ }^{13} \mathrm{C}$ -NMR (Nuclear Magnetic Resonance) experiments were performed in a Bruker $300 \mathrm{MHz}$ spectrometer at room temperature. For sample preparation, $250 \mu \mathrm{L}$ of the mother anolyte were extracted from electrochemical cell with a microsyringe and placed in a vial. Then, $250 \mu \mathrm{L}$ of a stock solution of ascorbic acid, o.4 $\mathrm{M}$ in $\mathrm{D}_{2} \mathrm{O}$ were added, and the sample was passed to the NMR tube for measurement.

Electrochemical ac impedance spectroscopy (EIS). EIS was performed by means of a typical three electrode cell in the frequency range from $100 \mathrm{kHz}$ to $0.1 \mathrm{~Hz}$ with 8 points per decade. The AC perturbation was $5 \mathrm{mV}$.

Characterization Methods. The chemical composition and the structure of the compounds were characterized by Infrared transmittance spectra (FTIR-ATR Cary 630 TR1 $\mathrm{Ph} 2$ ) and Raman spectroscopy (Renishaw in Via Reflex Raman confocal microscope, Gloucester- Shire, UK, light source: $514 \mathrm{~nm}$ ). Scanning electron microscopy (SEM) micrographs were acquired using a FEI Quanta 650 FEG ESEM at $20 \mathrm{kV}$ equipped with an Oxford EDX analyser (Oxford Instruments). Atomic resolution AC HAADF STEM and further EELS-STEM analyses were conducted at the FEI TITAN G3 50-300 PICO operated at $80 \mathrm{kV}$. Images have been analyzed using the DigitalMicrograph (Gatan Inc., USA) software package.

\section{Results and Discussion}

\section{Formate electrooxidation on CoFePB}

The oxidation performace of $\mathrm{CoFePB}$ was initially investigated at two different $\mathrm{pH}, 5$ and 13, via cyclic voltammetry (CV) of a $0.4 \mathrm{M}$ formate solution in $1 \mathrm{M} \mathrm{KNO}_{3}$ electrolyte (Figure 2). A characteristic formate oxidation wave appears at c.a. 0.92 and $0.43 \mathrm{~V}$ vs. NHE at $\mathrm{pH} 5$ and 13, respectively. In the first case, this onset potential is below the reversible $\mathrm{Co}^{\mathrm{II}} / \mathrm{Co}^{\mathrm{III}}$ redox couple in $\mathrm{CoFePB}$, c.a. $1.2 \mathrm{~V}$ vs. NHE (see inset of Figure $2 \mathrm{a}$ ) and in the latter case both potentials are fairly overlapping, since the $\mathrm{Co}^{\mathrm{II}} / \mathrm{Co}^{\mathrm{III}}$ redox potential is c.a. $0.4 \mathrm{~V}$ vs. NHE at $\mathrm{pH} 13 .{ }^{25}$ At both $\mathrm{pH}$ values, the onset of formate oxidation is well below the oxygen evolution reaction (OER) onset potential, which is c.a. 1.4 and $0.8 \mathrm{~V}$ vs. $\mathrm{NHE}$ at $\mathrm{pH} 5$ and 13, respectively. Therefore, the contribution of OER to the observed current can be considered minimal, consistent with our observed Faradaic efficiency (vide infra).

If we compare the results obtained at both $\mathrm{pH}$ values, the formate oxidation onset potential decreases with $\mathrm{pH}$ at 61 $\mathrm{mV} / \mathrm{pH}$. Such $\mathrm{pH}$ dependence is expected since formic/formate oxidation reaction will release protons as product, as shown in eq. 1:

$$
\mathrm{HCOOH} \rightarrow \mathrm{CO}_{2}+2 \mathrm{H}^{+}+2 \mathrm{e}^{-} E_{\mathrm{o}}=-0.2 \mathrm{OV}(1)
$$

In terms of overpotential ( $\eta$ ), it can be observed that the electrocatalytic activity of CoFePB is almost $\mathrm{pH}$ independent, with an onset of c.a. 1.4 V vs the thermodynamic potential of formate oxidation in both $\mathrm{pH}$ conditions. Similar conclusions were obtained in preliminar experiments with $0.4 \mathrm{M}$ formate/formic solution in $1 \mathrm{M} \mathrm{KNO}_{3}$ electrolyte and o.1 KPi buffer, which were carried out in a $\mathrm{pH}$ range from 1 to 13 (Figure $\mathrm{S}_{3}$ ). The current observed in the presence of $\mathrm{KPi}$ was lower than in its absence indicating an inhibitory effect of the phosphate anion on the catalysis, as confirmed by control experiments in the presence and absence of KPi (Figure $\mathrm{S}_{4}$ ). We hypothesize that this could be attributed to partial blocking of the catalytic sites and/or to displacement of reactive intermediate species by the weak adsorption of phosphate anions. 

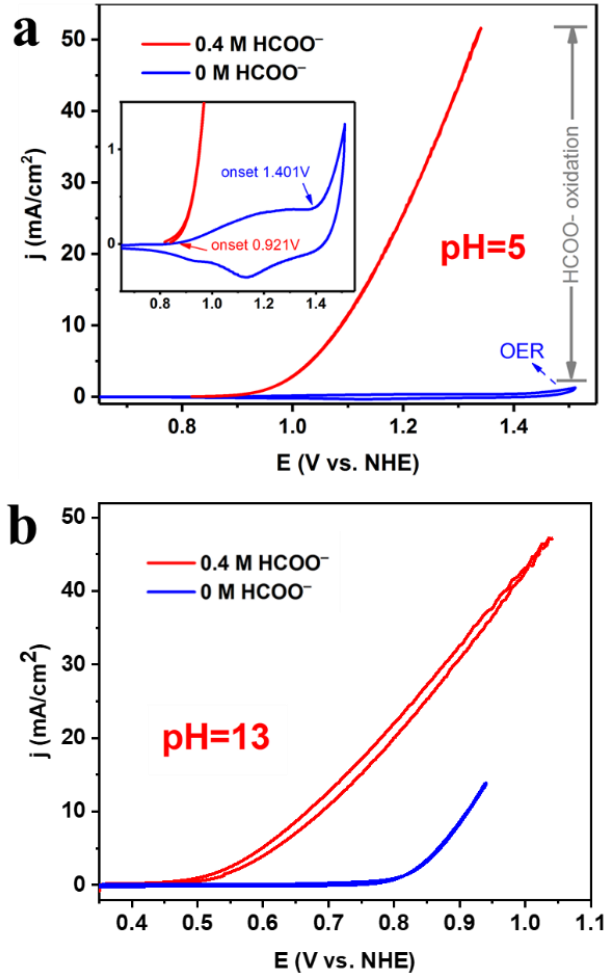

Figure 2. Cyclic voltammograms (CV) on CoFePB electrodes in (a) $\mathrm{pH} 5$ and (b) $\mathrm{pH} 13$ aqueous solutions in the presence (red line) and absence (blue line) of o.4 $\mathrm{M} \mathrm{HCOO}^{-}$. Electrolyte $1 \mathrm{M} \mathrm{KNO}_{3}$. Scan rate $5 \mathrm{mV} \mathrm{s}^{-1}$. Note, oxidation waves that are typical of formate oxidation with $\mathrm{Pt}$ or Pd are not observed here because CoFePB has a different electrochemical mechanism vide infra.

The linear $\mathrm{pH}$ dependence of the onset potential suggests that $\mathrm{CoFePB}$ is active towards the oxidation of formate over a wide $\mathrm{pH}$ range of 1-13 (Figure $\mathrm{S}_{3}$ ). Furthermore, current densities were consistent in all $\mathrm{pH}$ range studied, indicating negligible poisoning effect of $\mathrm{OH}^{-}$ions on the active electrocatalytic sites. This is particularly relevant since $\mathrm{OH}^{-}$anions are known to hinder the catalytic oxidation of small molecules oxidation, for example, in Pt based systems where severe poisoning above $\mathrm{pH} 11$ has been reported. ${ }^{30-33}$

We then examined the effect of formate concentration in alkaline, $\mathrm{pH}$ 13, and near-neutral, $\mathrm{pH}$ 5, conditions where maximum currents and minimum overpotentials were observed, respectively. Figure za shows the anodic polarization voltammograms for CoFePB electrodes in $\mathrm{pH} 5 \mathrm{KNO}_{3}$ $(\mathrm{M}$ ), as a function of formate concentration (up to $2 \mathrm{M}$ ) with a scan rate of $5 \mathrm{mV} / \mathrm{s}$. The presence of the formate oxidation wave is detected from low concentrations (10 $\mathrm{mM}$ ) with the appearance of anodic current with c.a. 0.92 $\mathrm{V}$ onset potential. The anodic current increases with concentration, reaching saturation at formate concentration above $1 \mathrm{M}$. Analogous results were found at $\mathrm{pH} 13$ (Figure $3 b)$, although higher concentration is needed to reach maximum current $(>2 \mathrm{M})$.

For both $\mathrm{pH} 5$ and 13 the electrochemical current is nearly identical when comparing anodic and cathodic sweeps at 5 $\mathrm{mV} / \mathrm{s}$ indicating pseudo-steady state reaction kinetics and, importantly, provides evidence against the catalyst poisoning by intermediates (Figure $\mathrm{S}_{5}$ ). This apparent absence of hysteresis between positive and negative scans indicates a negligible inhibition rate or a low tendency towards surface poisoning under these conditions (on this time scale and potential range), in contrast with the poisoning by $\mathrm{CO}$ ads species taking place on Pt-based electrocatalysts ${ }^{22,34}$ and, to a lesser extent, on Pd-based electrocatalysts. ${ }^{17,35}$
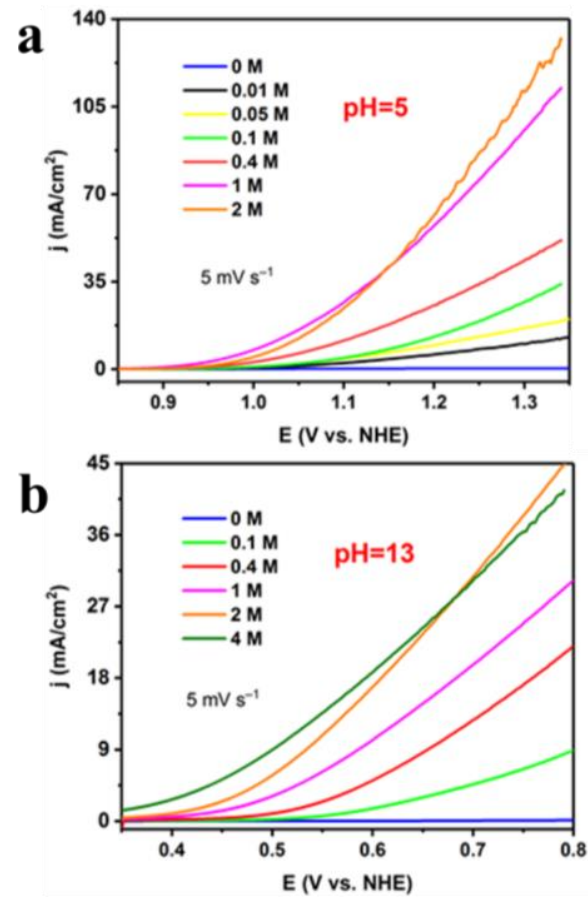

Figure 3. Anodic polarization data on CoFePB electrodes in 1 $\mathrm{M} \mathrm{KNO}_{3}$ aquesous electrolyte at $5 \mathrm{mV} / \mathrm{s}$ scan rates. Current density as a function of $\left[\mathrm{HCOO}^{-}\right]$at $(\mathbf{a}) \mathrm{pH}_{5}(\mathbf{b})$ and $\mathrm{pH} 13$.

\section{Selectivity of CoFePB to formate oxidation}

Regarding product selectivity, we analyzed the distribution of gaseous products during formate electro-oxidation at $1.19 \mathrm{~V}$ vs. NHE at $\mathrm{pH} 5$ (chronoamperometry shown in Figure S6b). By means of gas chromatography, only $\mathrm{CO}_{2}$ gas was detected, apart from nitrogen, used to initially deaerate the cell headspace volume, and oxygen amounts similar to those found when injecting $\mathrm{N}_{2}$ blank samples. No signals from other gaseous species were found. It is particularly significant the absence of $\mathrm{CO}$ which is a common by-product from the competing dehydration process. We did monitor quantitatively the $\mathrm{CO}_{2}$ production in the cell headspace by mass spectrometry at $\mathrm{pH} 5$, assisted by continuous flow of $\mathrm{N}_{2}$ carrier gas through the cell. We found a Faradaic efficiency towards $\mathrm{CO}_{2}$ production of $100 \%$ (within $<8 \%$ error) (Table 1). The MS experimental data are shown in detail in Tables $\mathrm{S}_{1}$ and $\mathrm{S}_{2}$. The high solubility of $\mathrm{CO}_{2}$ in alkaline media $\left(\mathrm{pH}_{13}\right)$ did not allow us to easily quantitify $\mathrm{CO}_{2}$ production under these conditions. We also recorded ${ }^{1} \mathrm{H}$ and ${ }^{13} \mathrm{C}$-NMR spectra of the aqueous solutions during the electrooxidation experiment (Figures $S_{7}$ ). No other side products, from more complex coupling reactions during electrooxidation, were detected in the electrolyte solution. 
Table 1. Theoretical vs experimental $\mathrm{CO}_{2}$ evolution on $\mathrm{CoFePB}$ electrodes during different chronopotentiometries at $\mathrm{pH}_{5}, 1 \mathrm{M} \mathrm{KNO}_{3}$ and $0.4 \mathrm{M}$ Formate.

\begin{tabular}{llll}
\hline $\begin{array}{l}\text { Current density/ mA } \\
\mathrm{cm}^{-2}\end{array}$ & 5 & 10 & 15 \\
$\begin{array}{l}\text { Theoretical CO } \\
\text { flow / NmL min }\end{array}$ & 0.037 & 0.075 & 0.112 \\
$\begin{array}{llll}\text { Experimental CO } \\
\text { flow / NmL min }\end{array}$ & $\begin{array}{l}0.037 \pm \\
0.003\end{array}$ & $\begin{array}{l}0.077 \pm \\
0.002\end{array}$ & $\begin{array}{l}0.113 \pm \\
0.003\end{array}$ \\
\hline
\end{tabular}

The selectivity of CoFePB towards $\mathrm{HCOO}^{-}$oxidation was additionally investigated by carrying out analogous aqueous electrolysis, at neutral $\mathrm{pH}$, in the presence of other small organic molecules with standard oxidation potentials in a similar range (eq. 2-5), including methanol, ethanol and acetic acid (Figure 4 ).

$$
\begin{aligned}
& \mathrm{CH}_{3} \mathrm{OH} \rightarrow \mathrm{CO}_{2}+6 \mathrm{H}^{+}+6 \mathrm{e}^{-} \mathrm{E}_{\mathrm{o}}=0.040 \mathrm{~V} \text { (2) } \\
& \mathrm{CH}_{3} \mathrm{CH}_{2} \mathrm{OH}+{ }_{3} \mathrm{H}_{2} \mathrm{O} \rightarrow{ }_{2} \mathrm{CO}_{2}+12 \mathrm{H}^{+}+12 \mathrm{e}^{-} \mathrm{E}_{\mathrm{o}}=0.085 \mathrm{~V}
\end{aligned}
$$$$
\mathrm{CH}_{3} \mathrm{COOH}+2 \mathrm{H}_{2} \mathrm{O} \rightarrow{ }_{2} \mathrm{CO}_{2}+8 \mathrm{H}^{+}+8 \mathrm{e}^{-} \mathrm{E}_{\mathrm{o}}=0.123 \mathrm{~V}(4)
$$

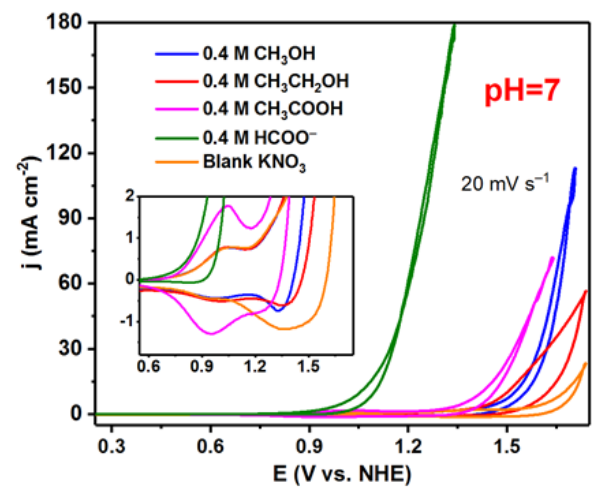

Figure 4. Cyclic Voltammograms $\left(20 \mathrm{mV} \mathrm{s}^{-1}\right)$ with CoFePB working electrode in the presence of small organic molecules (formic acid, methanol, ethanol and acetic acid) in 1 $\mathrm{M} \mathrm{KNO}_{3}$ aqueous solution at $\mathrm{pH} 7$.

Interestingly, CoFePB catalytic activity towards these other substrates was found to be very poor, comparatively. Only formate shows a significant anodic current at potentials below 1.3 V vs. NHE. More importantly, only the formate electrooxidation starts below the reversible CoFePB oxidation and well bellow the thermodynamic potential of water oxidation, with all other molecules showing oxidation waves at higher potentials. The difference between the electrooxidation of formate and the other organic molecules observed with the CoFePB catalyst is comparable with that found in literature with noble metal catalysts. For instance, the obtained onset potential of formic acid oxidation is typically o.1-0.4 V lower compared to that of methanol or ethanol oxidation with Pt or Pd catalysts, ${ }^{36-39}$ while this potential difference is of c.a. $0.5 \mathrm{~V}$ in our case.

The precise reason for this CoFePB selectivity towards formate oxidation (Figure 4) should be related to a different oxidation mechanism. This can be explained either by the simpler reaction pathway since it only involves a 2-electron transfer; whereas methanol oxidation to $\mathrm{CO}_{2}$, for example, would involve a four electron process along multiple proton removal, and attack by water; or also to the small size and negative charge of formate, making it a good ligand to replace water molecules bound to the active $\mathrm{Co}^{2+}$ sites, whereas the rest of the substrates are less prone to substitute bound water molecules, as first step in the catalytic cycle.

\section{Stability of the CoFePB electrocatalyst}

We also looked into the stability of the CoFePB anodes. The catalytic current density is relatively stable during chronoamperometry (CA) at both $\mathrm{pH} 5$ and $\mathrm{pH} 13$ for several hours (Figure S6). However, there is a small decrease in catalytic current that can be attributed to formate consumption in the finite-volume reaction vessel. For example, at $\mathrm{pH}$ 13, with $0.4 \mathrm{M}$ formate the current density decreases from $\sim 17$ to $\sim 13 \mathrm{~mA} \mathrm{~cm}^{-2}$, a $24 \%$ decrease, whereas the formate depletion (estimated from the average current, multiplied by the full time frame of the experiment, and converted to molar equivalents by the $2 \mathrm{e}^{\text {-/formate }}$ stoichiometry) was approximately $9 \%$. Thus, although we observe a decrease in catalytic current in finite volume $(30 \mathrm{~mL})$ set ups, we expect to maintain the catalytic current with in flow or by addition of formate when depleted.

Post-electrocatalytic SEM imaging shows no appreciable morphological changes in the CoFePB nanocubes (Figure S8a). Nanocubic shape and microporous structure is preserved without obvious signs of wearing and only showing partial aggregation. We observe small changes in the IR and Raman spectra that could be due to changes in the surface or minor structural changes that do not affect the observed electrocatalysis (Figures S8b-c and S9). Importantly, the catalyst has largely unchanged bands for the $\mathrm{CN}$ stretching from 2100 to $2000 \mathrm{~cm}^{-1}$ region. $\mathrm{CN}$ stretching is very sensitive to coordination number and oxidation state of the metal centers, ${ }^{40,41}$ and any in situ transformation would considerably affect the spectra. Hence, although minor changes are observed in the Raman spectra, the SEM, electrochemistry and vibrational spectroscopy are all consistent with the conclusion that the bulk of the material remains unchanged during extended electrolysis and no new catalytically active phases are formed.

Comparison with $\mathrm{CoO}_{\mathrm{x}}$ and benchmarking with PGM electrocatalysts

In oxidation electrocatalysis, it is known that many materials synthesized for catalysis actually serve as precatalysts to other heterogeneous phases formed during the oxidation. ${ }^{42-45}$ It can, therefore, be difficult to determine the genuine catalytic activity of a given material. For that purpose, we compared the catalytic activity of a $\mathrm{CoO}_{x}$ film in the same working conditions (Figure $\mathrm{S} 10$ ), as most plausible impurity arising from Co leaching, as observed for several oxidation electocatalysts. No additional oxidation events appeared in the presence of formate, confirming the negligible activity of $\mathrm{CoO}_{x}$ towards this organic compound. This precludes any participation of $\mathrm{CoO}_{x}$ traces in the excellent catalytic activity of CoFePB. Furthermore, we did not observe substantial changes in the electrochemistry during prolonged electrolysis, nor changes in the bulk structure of the CoFePB observed in the electron microscopy or vibrational spectroscopy. All of this evidence taken together 
provides a strong case that $\mathrm{CoFePB}$ is indeed the authentic formate oxidation catalyst.

To benchmark CoFePB as a formate oxidation catalyst we tested two noble metal catalysts, a Pt disk electrode and a carbon-supported palladium catalyst $(\mathrm{Pd}(5 \%) / \mathrm{C})$, by $\mathrm{CV}$ under the same operating conditions, i.w., with $0.4 \mathrm{M}$ formate at $\mathrm{pH}_{5}$ and 13 at a scan rate of $5 \mathrm{mV} / \mathrm{s}$ (Figure 5 ). The overpotential values required for the onset of formate oxidation can be observed in Table 2, and follow the trend of $\operatorname{Pd}(5 \%) / C<$ Pt $<$ CoFePB. ${ }^{1,39,46}$
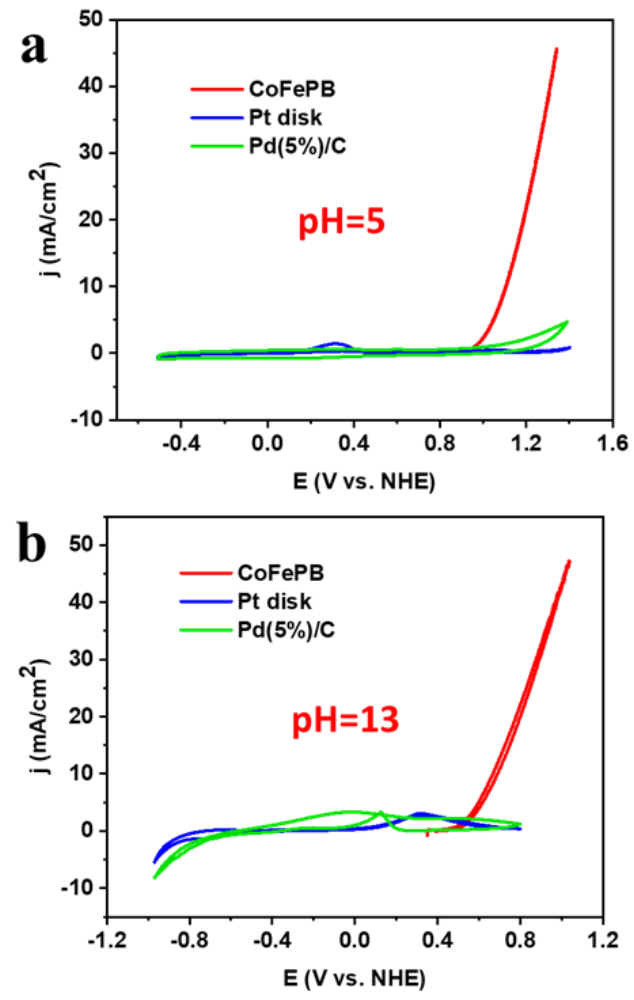

Figure 5. Cyclic Voltammograms $\left(5 \mathrm{mV} \mathrm{s}^{-1}\right)$ with CoFePB, Pt and $\mathrm{Pd}(5 \%) / C$ catalysts (a) $\mathrm{pH} 5$ and (b) $\mathrm{pH} 13$ aqueous solutions containing $0.4 \mathrm{M}$ formate and $1 \mathrm{M} \mathrm{KNO}_{3}$. CVs of the $\mathrm{Pt}$ and Pd catalysts can be observed in more detail in Figure Sil.

Table 2. Comparison of electrocatalytic activity of $\mathrm{Pd}(5 \%) / \mathrm{C}$, Pt disk and CoFePB electrodes obtained by $\mathrm{CV}$ under the conditions shown in Figure 5 , in terms of onset overpotential ( $\left.\eta_{\text {onset }}\right)$, maximum current density $\left(j_{\max }\right)$ obtained on the forward scan (at an overpotential $\eta_{\text {peak }}$ ), and current density $(j)$ obtained at given overpotentials $(\eta)$.

\begin{tabular}{|c|c|c|c|c|c|}
\hline \multirow{2}{*}{$\begin{array}{l}\text { Cata- } \\
\text { lyst }\end{array}$} & \multirow{2}{*}{$\begin{array}{c}\eta_{\text {onset }} \\
(\mathrm{V})\end{array}$} & \multirow{2}{*}{$\begin{array}{c}\mathrm{j}_{\max } \\
\left(\mathrm{mA} \mathrm{cm}^{-2}\right)\end{array}$} & \multicolumn{3}{|c|}{$\mathrm{j}\left(\mathrm{mA} \mathrm{cm} \mathrm{cm}^{-2}\right)$ at $\eta(\mathrm{V})$} \\
\hline & & & $\eta=1.2$ & $\eta=1.4$ & $\eta=1.6$ \\
\hline $\begin{array}{c}\mathrm{Pd} / \mathrm{C} \\
\left(\mathrm{pH}_{5}\right)\end{array}$ & 0.3 & $\begin{array}{c}0.6 \\
\text { (at } 0.8 \mathrm{~V} \text { ) }\end{array}$ & 0.5 & 0.7 & 1.4 \\
\hline $\begin{array}{c}\mathrm{Pt} \\
\left.(\mathrm{pH})_{5}\right)\end{array}$ & 0.5 & $\begin{array}{c}0.5 \\
\text { (at } 1.6 \mathrm{~V})\end{array}$ & 0.3 & 0.3 & 0.4 \\
\hline $\begin{array}{c}\mathrm{CoFePB} \\
\left(\mathrm{pH}_{5}\right)\end{array}$ & 1.4 & 10.1 & - & 0.2 & 10.1 \\
\hline $\begin{array}{c}\mathrm{Pd} / \mathrm{C} \\
(\mathrm{pH} 13)\end{array}$ & 0.4 & $\begin{array}{c}3.3 \\
(\text { at } 0.9 \mathrm{~V})\end{array}$ & 2.4 & 2.2 & 1.9 \\
\hline
\end{tabular}

\begin{tabular}{cccccc}
$\mathrm{Pt}$ & 0.7 & $\begin{array}{c}3.1 \\
(\mathrm{at} \mathrm{1.3} \mathrm{V})\end{array}$ & 2.1 & 2.0 & 0.9 \\
$(\mathrm{pH} \mathrm{13})$ & & 6.0 & - & 0.3 & 6.0 \\
$\mathrm{CoFePB}$ & 1.4 & & & & \\
$(\mathrm{pH} \mathrm{13})$ & & & & & \\
\hline
\end{tabular}

Another relevant feature from the CVs is the presence of several peaks in both forward and reverse scans on the $\mathrm{Pt}$ and Pd catalysts, in the potential range from -0.2 to $1.2 \mathrm{~V}$ vs. NHE at $\mathrm{pH} 5$ and from -0.6 to o.8 V vs. NHE at $\mathrm{pH} 13$. The presence of these peaks is consistent with literature on PGM-based catalysts $116,18,19,30-34,47-49$ and is related to the formate oxidation via either direct or indirect path (in the latter case through oxidation of adsorbed reaction intermediates) and to the oxidation/reduction of the PGM catalysts. Hence, adsorption of poisoning species like CO or hydroxyl groups on Pd and Pt leads to very low current densities at high overpotentials, as one can observe in Figure 5 as well as in Table 2 for $\eta=1.6 \mathrm{~V}$.

In stark contrast to both $\mathrm{Pt}$ and $\mathrm{Pd}(5 \%) / \mathrm{C}$, CoFePB displays no significant poisoning effect at high applied potential at any $\mathrm{pH}$ (Figures 2, 3, 5 and $\mathrm{S}_{3}$ ). The continuous increase of the current density at high potentials and the absence of any hysteresis denotes that this electrode is not poisoned by adsorbed species contrary to $\mathrm{Pt}$ and $\mathrm{Pd}$ catalysts. On the other hand, the concurrence of the $\mathrm{Co}^{2+} / \mathrm{Co}^{3+}$ redox couple at 1.2 and $0.4 \mathrm{~V}$ vs. NHE at $\mathrm{pH} 5$ and 13, respectively, does not passivate the catalyst, which seems to indicate that the oxidized state of CoFePB is the main active phase in the formate oxidation reaction. The implication of this resistance to poisoning and passivation is that $\mathrm{CoFePB}$ is a remarkably robust catalyst, since it does not suffer any decrease in current density with these processes, as state-ofthe-art Pt and Pd electrodes do.

The results shown herein thus open interesting prospects for the application of CoFePB as a fully noble-metal-free electrocatalyst for the development of direct formate fuel cells (which typically use Pd-based anodes). The performance, however, is presently limited by the onset potential of the formate oxidation which would reduce the operating potential of the fuel cell and hence lower the power efficiency of the device. In order to commercialize an electrode such as CoFePB, the onset potential for formate oxidation would need to be decreased to a value closer to the thermodynamic one while maintaining the high current densities observed herein. Furthermore, the high tolerance against poisoning of $\mathrm{CoFePB}$ and its formate oxidation selectivity in a wide range of $\mathrm{pH}$ make this material also a promising electrode for formate sensing applications, where the only noble-metal-free sensors reported so far consist of enzimes, which are limited to near-neutral $\mathrm{pH}$ conditions.

\section{Reaction dynamics}

Formate half-cell oxidation involves two electron transfers, one $\mathrm{C}-\mathrm{H}$ bond cleavage, deprotonation and, probably, adsorbed intermediates. The experimental Tafel plots obtained from steady-state current density show a significant dependence of the Tafel slope with $\mathrm{pH}$, showing $81 \mathrm{mV} \mathrm{dec}^{-}$ ${ }^{1}$ at $\mathrm{pH}_{5}$ but $130 \mathrm{mV} \mathrm{dec}^{-1}$ at $\mathrm{pH} 13$ (Figure $\mathrm{S}_{12}$ ). This change 
in Tafel slope indicates a different rate-determing step depending on $\mathrm{pH}$. In detail, the slope at $\mathrm{pH} 5$ is close to 60 $\mathrm{mV} \operatorname{dec}^{-1}$, that may be associated to a rate-limited step involving a two-electron transfer. On the contrary, the alkaline Tafel slope near $120 \mathrm{mV} \mathrm{dec}{ }^{-1}$ indicates the rate-determing step is more likely to be a $1 \mathrm{e}^{-}$transfer in a sequential reaction. ${ }^{50}$

Electrochemical impedance spectroscopy (EIS) is a helpful technique to understand electrochemical processes, able to distinguish between charge transport, charge transfer and electrocatalytic contributions to the electrode performance. Representative Nyquist plots for formate oxidation at different potentials at $\mathrm{pH} 5$ and 13 are shown in Figures $6 \mathrm{a}$ and $6 \mathrm{~b}$, respectively. In order to interpret the EIS results, we considered a simplified physical model for nanoporous electrodes (Figure 6c) which provides two arcs, consistently with the obtained Nyquist plots in all tested conditions. In this model, we considered that the FTO substrate $\left(\mathrm{C}_{\mathrm{FTO}}\right)$ is in contact with the liquid electrolyte, but does not transfer charge to the solution (as confirmed by blank experiments with bare FTO). Charge transport within the CoFePB layer is modeled through a resistor $\left(R_{t}\right)$, related to film conductivity. Charge transfer at the $\mathrm{CoFePB} /$ solution interface is modeled by a parallel RC element $\left(\mathrm{R}_{\mathrm{ct}} / \mathrm{C}_{\mathrm{CoF}-\mathrm{PB}}\right)$ and $\mathrm{R}_{\mathrm{s}}$ is the series resistance, which conveys the resistance of the solution, contact and wiring. The detailed explanation for the selection of this model can be found in the Supplementary discussion and Figure S13.

The CoFePB films were studied by EIS in $0.4 \mathrm{M}$ formate solution in different potential windows according to $\mathrm{pH}$ : 0.9 - $1.4 \mathrm{~V}$ vs NHE at $\mathrm{pH}$, and $0.4-0.8 \mathrm{~V}$ vs NHE at $\mathrm{pH} 13$, to avoid the contribution of the OER process taking place at more anodic potentials (Figure 2). In all cases, the EIS plots showed two well-defined semicircles confined in the first quadrant. At $\mathrm{pH}$ 5, the low frequency loop exhibits a Tafel slope of $69 \mathrm{mV} \mathrm{dec}^{-1}$ (Figure S14), in good agreement with the chronoamperometric measurements (Figure S12a). This supports the assignment of this low-frequency loop to the charge transfer process occurring at the $\mathrm{CoFePB} /$ solution interface during formate oxidation. At both $\mathrm{pH} 5$ and $\mathrm{pH} 13$ the arc diameter decreases when potential is increased. This is in contrast to the case of electrooxidation on precious metal electrocatalysts, where a negative Faradaic impedance appears due to the oxidative removal of passivating $\mathrm{CO}_{\text {ads }}$ that blocks active sites. ${ }^{18,51,52}$ This supports again the absence of $\mathrm{CO}$ production and/or $\mathrm{CO}$ passivation in the case of our CoFePB films. At both $\mathrm{pH}$ conditions, the high frequency arc diameter also decreases when increasing the applied potentials. We associated this arc to the charge transport process across the CoFePB film, a semiconductor with strong charge localization. 53,54 This hypothesis is in good agreement with the EIS data obtained with a CoFePB film in aqueous solution in the absence of formate (Figures $\mathrm{S}_{15}$ and $\mathrm{S}_{16}$ ). The charge transport kinetics for formate oxidation decrease with applied potential down to the anodic reversible $\mathrm{Co}^{2+} / \mathrm{Co}^{3+}$ redox event at both $\mathrm{pH}$, and then remains constant at higher potentials (Figures 6d, 6e and S16a).

By comparison with the electrode performance in the absence of formate, only one depressed high frequency semicircle followed by a quasi-vertical line (pure capacitance reflecting a blocking interface) is observed at $\mathrm{pH}_{5}$ in the potential window of $0.9 \mathrm{~V}-1.4 \mathrm{~V}$ vs NHE. This confirms the poor catalytic activity of $\mathrm{CoFePB}$ for water oxidation in the formate oxidation potential range, and confirms that formate oxidation is the only significant redox event at $\mathrm{pH} 5$. At $\mathrm{pH}$ 13, the charge transfer resistance that we assign to water oxidation is delayed around $300 \mathrm{mV}$ compared to that for formate oxidation, also reflecting that formate oxidation is still the dominant process in the potential window studied (Figure S16b). Finally, $R_{s}$ is identical for both water oxidation and formate oxidation, as expected (Figure $\mathrm{S} 16 \mathrm{c})$. The extracted capacitiances are consistent with the above interpretation (Figure $\mathrm{S}_{17}$ ). Indeed, the high capacitances of the CoFePB layer (around $10^{-2}-10^{-1} \mathrm{~F} \cdot \mathrm{cm}^{-2}$ ) are consistent with a highly porous layer, with a contribution from redox events, like $\mathrm{Co}^{2+} / \mathrm{Co}^{3+}$. Also, the values for $\mathrm{C}_{\mathrm{FTO}}$ are qualitatively in good agreement with the blank measurements carried out on bare FTO substrate in contact with the solution.
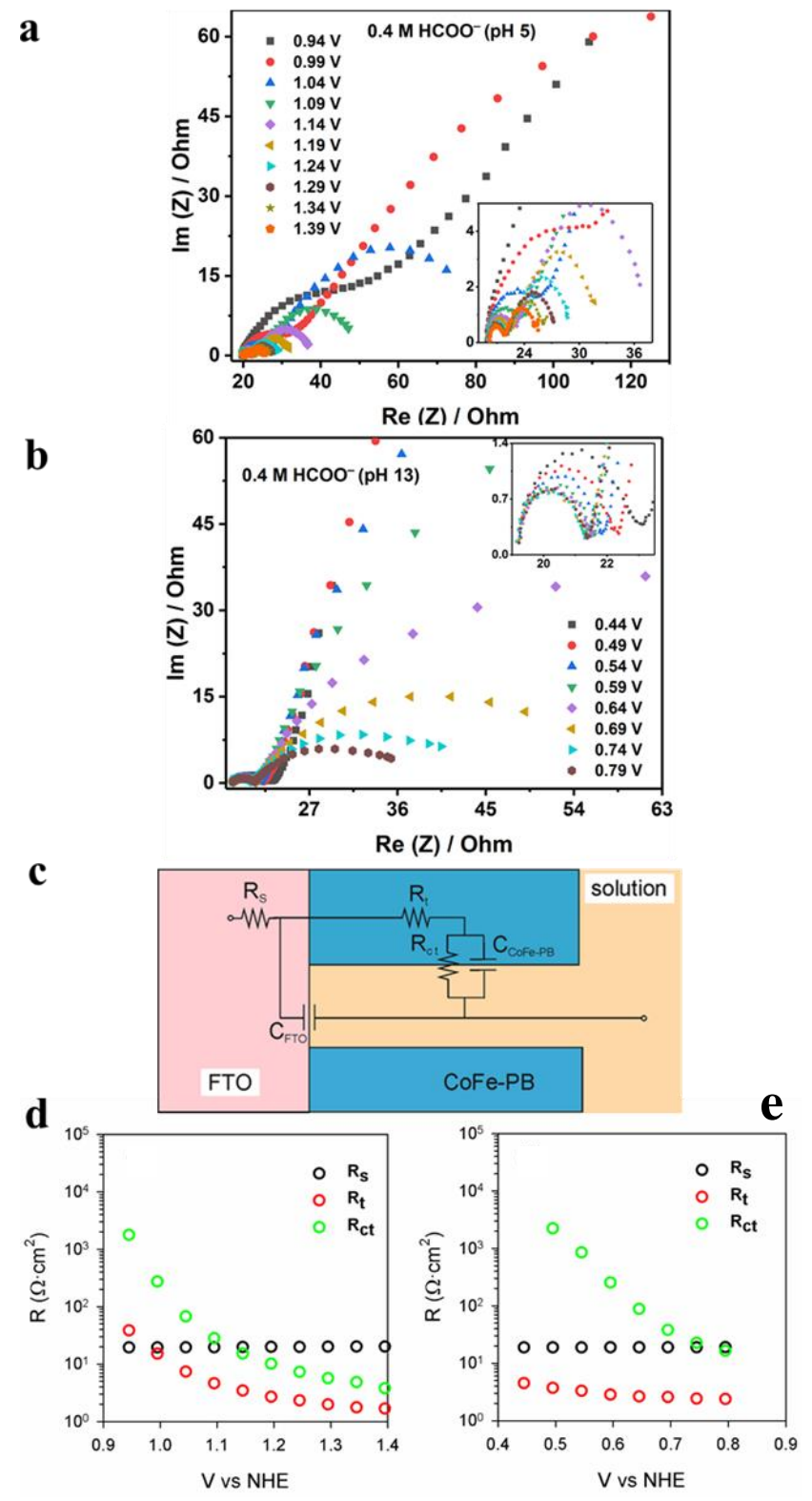

Figure 6. EIS data for CoFePB electrodes. Representative Nyquist plots for formate oxidation at $(\mathbf{a}) \mathrm{pH} 5$ or $(\mathbf{b}) \mathrm{pH} 13$. 
(c) Equivalent circuit employed to fit the experimental impedance data. (d) Resistances extracted from the Nyquist plots at $\mathrm{pH} 5$ for formate oxidation. (e) Resistances extracted from the Nyquist plots at $\mathrm{pH} 13$ for formate oxidation. Series resistance $\left(R_{s}\right)$, charge transfer resistance $\left(R_{c t}\right)$ and transport resistance $\left(R_{t}\right)$ are showed in black, green and red, respectively.

Hole transfer to the solution is the limiting step for formate oxidation at low overpotentials, between 0.90 and $1.15 \mathrm{~V}$ vs $\mathrm{NHE}$ at $\mathrm{pH}$, and between 0.40 and o.8o V vs NHE at $\mathrm{pH}$ 13 (since $R_{c t}$ is tha highest circuit resistance). Conversely, at more anodic applied potentials the series resistance becomes the limiting factor, which can be mainly ascribed to the electrolyte conductivity, apart from connections and wiring. This suggests that device engineering must be improved targeting technological applications of CoFePB electrodes.

\section{Conclusions}

In this manuscript, we have disclosed the activity of the Co-Fe Prussian Blue derivative to catalyze the oxidation of formate and formic acid in aqueous solutions. This catalyst offers quantitative selectivity towards $\mathrm{CO}_{2}$ with Faradaic efficiency near $100 \%$ and is active in the $\mathrm{pH}$ 1-13 range. $\mathrm{CoFePB}$ is selective towards formate oxidation, whereas methanol, ethanol, acetate and water are all oxidized at much higher overpotentials. Long-term experiments and post-catalysis characterization provide evidence supporting the high stability of CoFePB, and importantly the absence of other species that are catalytically active towards formate oxidation-thereby implying that CoFePB is the true catalytically active species. Control expreriments with state-of-the-art $\mathrm{Pt}$ and $\mathrm{Pd}(5 \%) / \mathrm{C}$ show that although the noble metal catalysts are poisoned by adsorbed intermediates at high current density, CoFePB remains active and is able to achieve stable current densities outperforming its noble metal competitors. Charge transport and charge transfer steps have been identified by EIS, being hole transfer the limiting factor for formate oxidation at moderate applied potentials, and revealing that device engineering should be optimized for relevant technological appilcations in formate fuel cell devices and/or formate sensors.

\section{ASSOCIATED CONTENT}

\section{Supporting Information}

Additional electrochemical data, composition and structural characterization by IR and Raman, STEM, EELS, NMR and MS are available free of charge via the Internet at http://pubs.acs.org.

\section{AUTHOR INFORMATION}

\section{Corresponding Author}

*jrgalan@iciq.es

\section{ORCID}

J. Arbiol: ooo-00o2-0695-7253

S. J. Folkman: oooo-ooo2-8124-7253

J. R. Galan-Mascaros: oooo-ooo1-7983-9762

J. González-Cobos: oooo-0003-4426-588X
Notes

The authors declare no competing financial interests.

\section{ACKNOWLEDGMENT}

We thank Dr. Hong-Chu Du and Dr. Paul Paciok from Ernst-Ruska Centre for Microscopy and Spectroscopy with Electrons for their contribution in high-angle annular dark-field (HAADF)-STEM and EELS characterization. We acknowledge Prof. Julio Lloret-Fillol and Sergio Fernández from ICIQ for their helpful discussion.

The authors gratefully acknowledge financial support from the FEDER/Ministerio de Ciencia e Innovación - Agencia Estatal de Investigación through projects RTI2018-095618B-100 and ENE2017-85087-C3; the Generalitat de Catalunya (2017-SGR-1406 and 2017-SGR-327), and the CERCA Programme/Generalitat de Catalunya. I.S.M. thanks Marie Skłodowska-Curie CO-FUND program PRO-BIST for her postdoctoral contract (grant agreement No. 754510). ICN2 is supported by the Severo Ochoa program from Spanish MINECO (Grant No. SEV-2017-0706). ICN2 and ICIQ acknowledge funding from the BIST Ignite project InWOC2.

\section{REFERENCES}

(1) An, L.; Chen, R. Direct formate fuel cells: A review. J. Power Sources 2016, 320, 127.

(2) Singh, A. K.; Singh, S.; Kumar, A. Hydrogen energy future with formic acid: A renewable chemical hydrogen storage system. Catal. Sci. Technol. 2016, 6, 12.

(3) Mansor, M.; Timmiati, S. N.; Lim, K. L.; Wong, W. Y.; Kamarudin, S. K.; Nazirah Kamarudin, N. H. Recent progress of anode catalysts and their support materials for methanol electrooxidation reaction. Int. J. Hydrogen Energy 2019, 44, 14744.

(4) Monyoncho, E. A.; Woo, T. K.; Baranova, E. A. In SPR Electrochemistry 2019; Vol. 15, p 1.

(5) González-Cobos, J.; Baranton, S.; Coutanceau, C. Development of Bismuth-Modified PtPd Nanocatalysts for the Electrochemical Reforming of Polyols into Hydrogen and ValueAdded Chemicals. ChemElectroChem 2o16, 3, 1694.

(6) Caravaca, A.; Garcia-Lorefice, W. E.; Gil, S.; de Lucas-Consuegra, A.; Vernoux, P. Towards a sustainable technology for $\mathrm{H} 2$ production: Direct lignin electrolysis in a continuous-flow Polymer Electrolyte Membrane reactor. Electrochem. Commun. 2019, 100,43 .

(7) Waldie, K. M.; Brunner, F. M.; Kubiak, C. P. Transition Metal Hydride Catalysts for Sustainable Interconversion of $\mathrm{CO}_{2}$ and Formate: Thermodynamic and Mechanistic Considerations. ACS Sustainable Chem. Eng. 2018, 6, 6841.

(8) Lu, X.; Wu, Y.; Yuan, X.; Wang, H. An Integrated $\mathrm{CO}_{2}$ Electrolyzer and Formate Fuel Cell Enabled by a Reversibly Restructuring Pb-Pd Bimetallic Catalyst. Angew. Chem. Int. Ed. 2019, 58,4031 .

(9) Pilas, J.; Yazici, Y.; Selmer, T.; Keusgen, M.; Schöning, M. J. Optimization of an amperometric biosensor array for simultaneous measurement of ethanol, formate, d- and l-lactate. Electrochim. Acta 2017, 251, 256.

(10) Röhlen, D. L.; Pilas, J.; Dahmen, M.; Keusgen, M.; Selmer, T.; Schöning, M. J. Toward a Hybrid Biosensor System for Analysis of Organic and Volatile Fatty Acids in Fermentation Processes. Front. Chem. 2018, 6, 284.

(11) Daniele, S.; Bragato, C.; Battistel, D. BismuthCoated Mesoporous Platinum Microelectrodes as Sensors for Formic Acid Detection. Electroanalysis 2012, 24, 759.

(12) Mak, K. K. W.; Wollenberger, U.; Scheller, F. W. Renneberg, R. An amperometric bi-enzyme sensor for determination of formate using cofactor regeneration. Biosens. Bioelectron. 2oo3, 18, 1095. 
(13) Soloveichik, G. L. Liquid fuel cells. Beilstein J. Nanotechnol. 2014, 5, 1399.

(14) Direct liquid fuel cells: A review, Ong, B. C.; Kamarudin, S. K.; Basri, S. Int. J. Hydrogen Energy 2017, 42, 10142.

(15) Yu, X.; Pickup, P. G. Recent advances in direct formic acid fuel cells (DFAFC). J. Power Sources 20o8, 182, 124.

(16) Douk, A. S.; Farsadrooh, M.; Damanigol, F.; Moghaddam, A. A.; Saravani, H.; Noroozifar, M. Porous threedimensional network of $\mathrm{Pd}-\mathrm{Cu}$ aerogel toward formic acid oxidation. RSC Adv. 2018, 8, 23539.

(17) Xi, Z.; Li, J.; Su, D.; Muzzio, M.; Yu, C.; Li, Q.; Sun, $S$. Stabilizing CuPd Nanoparticles via CuPd Coupling to $\mathrm{WO}_{2.72}$ Nanorods in Electrochemical Oxidation of Formic Acid. J. Am. Chem. Soc. 2017, 139, 15191.

(18) Chen, W.; Kim, J.; Sun, S.; Chen, S. Electrooxidation of formic acid catalyzed by FePt nanoparticles. Phys. Chem. Chem. Phys. 2006, 8, 2779.

(19) Sankar, S.; Anilkumar, G. M.; Tamaki, T.; Yamaguchi, T. Binary Pd-Ni Nanoalloy Particles over Carbon Support with Superior Alkaline Formate Fuel Electrooxidation Performance. ChemCatChem 2019, 11, 4731.

(20) Bisht, A.; Pentyala, P.; Deshpande, P. A.; Sharma, S. $\mathrm{La}_{0.80} \mathrm{Sr}_{0.20} \mathrm{CoO}_{3}$ as a noble-metal-free catalyst for the direct oxidation of formic acid under zero applied potential. Electrochem. Commun. 2019, 99, 1.

(21) Cracknell, J. A.; Vincent, K. A.; Armstrong, F. A. Enzymes as Working or Inspirational Electrocatalysts for Fuel Cells and Electrolysis. Chem. Rev. 20o8, 108, 2439.

(22) Robinson, W. E.; Bassegoda, A.; Reisner, E.; Hirst, J. Oxidation-State-Dependent Binding Properties of the Active Site in a Mo-Containing Formate Dehydrogenase. J. Am. Chem. Soc. 2017, 139, 9927.

(23) Galan, B. R.; Schöffel, J.; Linehan, J. C.; Seu, C.; Appel, A. M.; Roberts, J. A. S.; Helm, M. L.; Kilgore, U. J.; Yang, J. Y.; DuBois, D. L.; Kubiak, C. P. Electrocatalytic Oxidation of Formate by $\left[\mathrm{Ni}\left(\mathrm{PR}_{2} \mathrm{NR}_{2}^{\prime}\right)_{2}\left(\mathrm{CH}_{3} \mathrm{CN}\right)\right]^{2+}$ Complexes. J. Am. Chem. Soc. 2011, 133, 12767 .

(24) Seu, C. S.; Appel, A. M.; Doud, M. D.; DuBois, D. L.; Kubiak, C. P. Formate oxidation via $\beta$-deprotonation in $\left[\mathrm{Ni}\left(\mathrm{PR}_{2} \mathrm{NR}_{2}^{\prime}\right)_{2}\left(\mathrm{CH}_{3} \mathrm{CN}\right)\right]^{2+}$ complexes. Energy Environ. Sci. 2012, 5, 6480 .

(25) Han, L.; Tang, P.; Reyes-Carmona, Á.; RodríguezGarcía, B.; Torréns, M.; Morante, J. R.; Arbiol, J.; Galan-Mascaros, J. R. Enhanced Activity and Acid pH Stability of Prussian Blue-type Oxygen Evolution Electrocatalysts Processed by Chemical Etching. J. Am. Chem. Soc. 2016, 138, 16037 .

(26) Rodríguez-García, B.; Reyes-Carmona, Á.; Jiménez-Morales, I.; Blasco-Ahicart, M.; Cavaliere, S.; Dupont, M.; Jones, D.; Rozière, J.; Galán-Mascarós, J. R.; Jaouen, F. Cobalt hexacyanoferrate supported on Sb-doped $\mathrm{SnO}_{2}$ as a non-noble catalyst for oxygen evolution in acidic medium. Sustainable Energy Fuels 2018, 2, 589 .

(27) Garcés-Pineda, F. A.; González-Cobos, J.; Torrens, M.; Galán-Mascarós, J. R. Fluorine-Doped Tin Oxide/Alumina as Long-Term Robust Conducting Support for EarthAbundant Water Oxidation Electrocatalysts. ChemElectroChem 2019, 6,2282 .

(28) Goberna-Ferrón, S.; Hernández, W. Y.; Rodríguez-García, B.; Galán-Mascarós, J. R. Light-driven water oxidation with metal hexacyanometallate heterogeneous catalysts. ACS Catal. 2014, 4, 1637.

(29) Choun, M.; Ham, K.; Shin, D.; Lee, J. K.; Lee, J. Catalytically active highly metallic palladium on carbon support for oxidation of $\mathrm{HCOO}^{-}$. Catal. Today 2017, 295, 26.

(30) Joo, J.; Choun, M.; Jeong, J.; Lee, J. Influence of Solution pH on Pt Anode Catalyst in Direct Formic Acid Fuel Cells. ACS Catal. 2015, 5, 6848.

(31) Joo, J.; Uchida, T.; Cuesta, A.; Koper, M. T. M.; Osawa, M. The effect of $\mathrm{pH}$ on the electrocatalytic oxidation of formic acid/formate on platinum: A mechanistic study by surface-enhanced infrared spectroscopy coupled with cyclic voltammetry. Electrochim. Acta 2014, 129, 127.
(32) Brimaud, S.; Solla-Gullón, J.; Weber, I.; Feliu, J. M.; Behm, R. J. Formic Acid Electrooxidation on Noble-Metal Electrodes: Role and Mechanistic Implications of $\mathrm{pH}$, Surface Structure, and Anion Adsorption. ChemElectroChem 2014, 1, 1075.

(33) Perales-Rondón, J. V.; Brimaud, S.; Solla-Gullón, J.; Herrero, E.; Jürgen Behm, R.; Feliu, J. M. Further Insights into the Formic Acid Oxidation Mechanism on Platinum: $\mathrm{pH}$ and Anion Adsorption Effects. Electrochim. Acta 2015, 180, 479.

(34) Okamoto, H.; Kon, W.; Mukouyama, Y. Stationary Voltammogram for Oxidation of Formic Acid on Polycrystalline Platinum. J. Phys. Chem. B 2004, 108, 4432.

(35) Hong, J. W.; Kim, D.; Lee, Y. W.; Kim, M.; Kang, S. W.; Han, S. W. Atomic-distribution-dependent electrocatalytic activity of Au-Pd bimetallic nanocrystals. Angew. Chem. Int. Ed. 2011, 50, 8876 .

(36) Nonaka, H.; Matsumura, Y. Electrochemical oxidation of carbon monoxide, methanol, formic acid, ethanol, and acetic acid on a platinum electrode under hot aqueous conditions. $J$. Electroanal. Chem. 2002, 520, 101.

(37) Wang, X.; Wang, W.; Qi, Z.; Zhao, C.; Ji, H.; Zhang, Z. High catalytic activity of ultrafine nanoporous palladium for electro-oxidation of methanol, ethanol, and formic acid. Electrochem. Commun. 2009, 11, 1896.

(38) Hsieh, C.-T.; Hsiao, H.-T.; Tzou, D.-Y.; Yu, P.-Y.; Chen, P.-Y.; Jang, B.-S. Electro-oxidation of methanol and formic acid on platinum nanoparticles with different oxidation levels. Mater. Chem. Phys. 2015, 149-150, 359.

(39) Yu, X.; Manthiram, A. Catalyst-selective, scalable membraneless alkaline direct formate fuel cells. Appl. Catal. B: Environ. 2015, 165, 63.

(40) Alsac, E. P.; Ulker, E.; Nune, S. V. K.; Dede, Y.; Karadas, F. Tuning the Electronic Properties of Prussian Blue Analogues for Efficient Water Oxidation Electrocatalysis: Experimental and Computational Studies. Chem. Eur. J. 2018, 24, 4856.

(41) Aksoy, M.; Nune, S. V. K.; Karadas, F. A Novel Synthetic Route for the Preparation of an Amorphous Co/Fe Prussian Blue Coordination Compound with High Electrocatalytic Water Oxidation Activity. Inorg. Chem. 2016, 55, 4301.

(42) Stracke, J. J.; Finke, R. G. Electrocatalytic Water Oxidation Beginning with the Cobalt Polyoxometalate $\left[\mathrm{CO}_{4}\left(\mathrm{H}_{2} \mathrm{O}\right)_{2}\left(\mathrm{PW}_{9} \mathrm{O}_{34}\right)_{2}\right]^{10-}$ : Identification of Heterogeneous $\mathrm{CoO}_{x}$ as the Dominant Catalyst. J. Am. Chem. Soc. 2011, 133, 14872.

(43) Ullman, A. M.; Liu, Y.; Huynh, M.; Bediako, D. K.; Wang, H.; Anderson, B. L.; Powers, D. C.; Breen, J. J.; Abruña, H. D.; Nocera, D. G. Water Oxidation Catalysis by $\mathrm{Co}(\mathrm{II})$ Impurities in $\mathrm{Co}(\mathrm{III})_{4} \mathrm{O}_{4}$ Cubanes. J. Am. Chem. Soc. 2014, 136, 17681.

(44) Burke, M. S.; Kast, M. G.; Trotochaud, L.; Smith, A. M.; Boettcher, S. W. Cobalt-Iron (Oxy)hydroxide Oxygen Evolution Electrocatalysts: The Role of Structure and Composition on Activity, Stability, and Mechanism. J. Am. Chem. Soc. 2015, 137, 3638.

(45) Folkman, S. J.; Soriano-Lopez, J.; GalánMascarós, J. R.; Finke, R. G. Electrochemically Driven WaterOxidation Catalysis Beginning with Six Exemplary Cobalt Polyoxometalates: Is It Molecular, Homogeneous Catalysis or Electrode-Bound, Heterogeneous $\mathrm{CoO}_{x}$ Catalysis? J. Am. Chem. Soc. 2018, 140, 12040 .

(46) Jeong, S.; Shin, W. Triple-pulse Method for Monitoring Formate in $\mathrm{CO}_{2}$ Conversion Process. Electroanalysis 2016, 28, 1437.

(47) Jiang, J.; Scott, J.; Wieckowski, A. Direct evidence of a triple-path mechanism of formate electrooxidation on Pt black in alkaline media at varying temperature. Part I: The electrochemical studies. Electrochim. Acta 2013, 104, 124.

(48) Wang, J.; Liu, C.; Banis, M. N.; Cheng, N.; Riese, A.; Wang, S.; Sun, X. Superior anti-poisoning performance of graphenes versus carbon nanotubes as $\mathrm{Pt}$ catalysts supports for formate oxidation. Int. J. Hydrogen Energy 2016, 41, 936.

(49) Yépez, O.; Scharifker, B. R. Oxidation of formate on hydrogen-loaded palladium. Int. J. Hydrogen Energy 2002, 27, 99.

(50) Pletcher, D. In A First Course in Electrode Processes; 2nd ed.; RSC Publishing: 2009. 
(51) Lu, Y.; Chen, W. Nanoneedle-covered Pd-Ag nanotubes: High electrocatalytic activity for formic acid oxidation. J. Phys. Chem. C 2010, 114, 21190.

(52) Lu, Y.; Chen, W. PdAg alloy nanowires: Facile one-step synthesis and high electrocatalytic activity for formic acid oxidation. ACS Catal. 2012, 2, 84.
(53) García-Jareño, J. J.; Navarro, J. J.; Roig, A. F.; Scholl, H.; Vicente, F. Impedance analysis of Prussian Blue films deposited on ITO electrodes. Electrochim. Acta 1995, 40, 1113.

(54)

García-Jareño, J. J.; Navarro-Laboulais, J.; Vicente, F. Charge transport in Prussian Blue films deposited on ITO electrodes. Electrochim. Acta 1996, 41, 835. 
ToC:

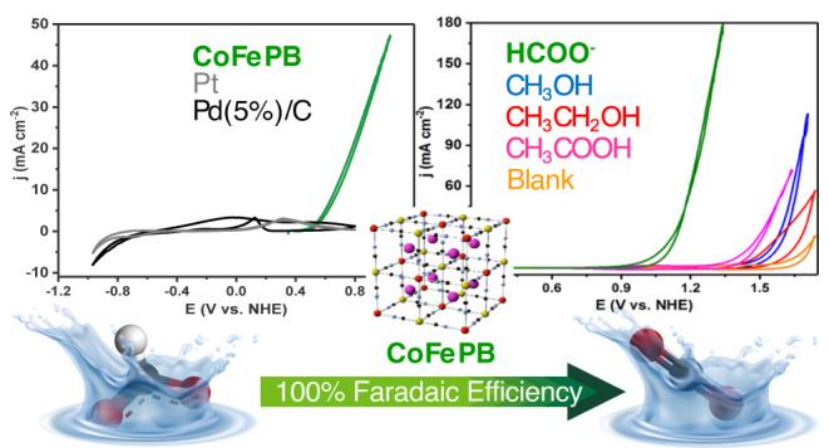

